\title{
PRODUÇÃO TEXTUAL: UM OLHAR ATENTO À REFERENCIAÇÃO
}

Marta Aparecida Paulo FERREIRA ${ }^{1}$

Doutoranda em Língua Portuguesa - PUC - SP

Neste ensaio, propomos uma reflexão sobre a referenciação nas produções textuais de alunos e sobre os percalços enfrentados por professores no ensino desse conteúdo, uma vez que a referenciação é fundamental para o sentido do texto, responsável por estabelecer relação entre coesão e coerência.

O professor precisa estar atento para não tornar o aluno um mero identificador de referentes textuais, para isso, precisa adotar estratégias de ensino e elaborar atividades significativas que deem autonomia à leitura e à escrita do aluno. Sabendo da deficiência na formação de muitos educadores, o Estado e as escolas devem capacitar os professores de Língua Portuguesa. Só assim, esse trabalho surtirá efeitos no árduo caminho que é o ensino de produção textual.

Por estarmos inseridos no processo educacional e na área da linguagem, temos nossas percepções de que há professores de escolas públicas e privadas que ainda priorizam o ensino de gramática pautado em regras. Temos consciência da importância da gramática no ensino de língua, desde que trabalhada de modo contextualizado, mas também entendemos que priorizar a atividade de produção de texto leva o aluno a desenvolver sua capacidade de refletir sobre a linguagem, sobre seu funcionamento e seu uso de forma dinâmica.

Ainda em se tratando de produção textual, no que diz respeito à referenciação, muitos professores limitam-se às informações presentes nos textos, ensinando e corrigindo as sequencializações, ou seja, atentam-se apenas às formas de estabelecer ligação entre as partes do texto, sem observar o dinâmico processo de construção dos referentes e a função sociocognitiva desses elementos.

A referenciação pode ser entendida como o processo de construção referencial no discurso. Segundo Cavalcante (2014, p. 27), as novas contribuições da Linguística Textual nos mostram que "a referenciação é uma proposta teórica que vem contribuir para o caráter dinâmico do processo de construção dos referentes no texto". Quando produzimos um texto, estabelecemos os referentes por meio de expressões referenciais, que são recursos linguísticos inseridos no cotexto, assim, realizamos automaticamente o processo da referenciação, que

\footnotetext{
${ }^{1}$ Endereço eletrônico: martapaulo@uol.com.br
} 
envolve tanto elementos textuais e seus referentes quanto o contexto. $\mathrm{O}$ caráter dinâmico da referenciação, ressaltado por Cavalcante (2014), ocorre quando um elemento novo é introduzido, reativado ou desfocalizado no texto. Esse elemento se forma na mente do produtor em decorrência de fatores como conhecimento de mundo e conhecimento linguístico, que vão se desenvolvendo na proporção em que lhes atribuímos significações.

De modo a embasar nossa reflexão, buscamos os fundamentos teóricos da Linguística Textual, notadamente a vertente sociocognitivo-interacionista da linguagem, segundo a qual a base da atividade linguística está na interação entre interlocutores em um dado evento comunicativo. Dessa perspectiva, a Linguística Textual passa a ter como principais objetos de estudo as questões de significação e de linguagem, ou seja, as relações entre linguagem e representação do mundo (KOCH, 2014).

Nessa direção, admitimos que os referentes surgem da inter-relação entre as práticas sociais e a língua, isto é, os referentes não correspondem diretamente às entidades existentes na realidade; eles são construções mentais realizadas no discurso, sendo antes "objetos-dediscurso". Assim, "os chamados 'objetos-de-discurso' não preexistem 'naturalmente' à atividade cognitiva e interativa dos sujeitos falantes, mas devem ser concebidos como produtos - fundamentalmente culturais - desta atividade. (APOTHÉLOZ; REICHERBÉGUELIN, 1995, p. 228)

Para Cavalcante (2003), o referente não está no mundo, nem no texto, nem está preestabelecido na mente dos interlocutores; ele é uma representação, uma imagem que se constrói no e pelo discurso, ao longo do qual pode ser introduzido, ativado e/ou reativado. Os referentes podem ser apontados por diferentes tipos de expressões referenciais no texto, como nomes próprios; pronomes demonstrativos, possessivos ou indefinidos; grupos nominais com artigo definido ou indefinido; grupos nominais modificados por advérbio ou por expressões que indiquem ordenação; elipses de pronomes ou de grupos nominais.

Uma vez que admitimos serem os referentes resultados da prática social, faz-se necessário refletir sobre a referenciação. Neste ensaio, defendemos a ideia de que a referenciação é uma ampliação do conceito de referência, um processo ao longo do qual construímos sentidos. Trata-se de uma atividade sociocognitivo-discursiva (KOCH; MARCUSCHI, 1998).

Desse modo, os referentes podem ser representados por uma expressão referencial no contexto, podem ser situados ou até pressupostos no cenário no momento da comunicação, ou, ainda, podem estar estabelecidos na memória comum dos participantes, ou em mais de um desses espaços. 
A referência, compreendida como processo de referenciação, não se realiza com o simples uso de expressões referenciais; ela vai além disso, uma vez que o referente se materializa a partir de um conjunto de ações, do modo como os interlocutores organizam suas ações e como constroem sentidos no evento comunicativo. Dessa ótica, a referenciação é entendida como o movimento, prospectivo ou retrospectivo, pelo qual apontamos para outros elementos do texto.

Como Silva, Cavalcante e Brito (2015, p. 279) ressaltam, “entre as 'palavras' e as 'coisas', há uma mediação que comporta o sentido, nomeada de 'referente', visto que a realidade como tal é intangível, de modo que a única realidade perceptível ao homem se dá pela língua natural”.

O processo de referenciação apresenta três categorias gerais: introdução referencial, anáfora e dêixis. A introdução referencial, introduz o referente pela primeira vez no texto. De acordo com Cavalcante (2014, p. 54), a

[...] introdução referencial ocorre quando um referente, ou objeto de discurso, 'estreia' no texto de alguma maneira. Isso pode se dar pelo modo mais evidente: por meio do emprego de uma expressão referencial ainda não mencionada anteriormente.

Já a anáfora é uma expressão referencial cuja função é dar continuidade a uma referência ao longo do texto, de modo que é o recurso responsável pela coesão textual. A anáfora pode ser direta, ou correferencial, quando determinada expressão retoma o mesmo referente já introduzido no texto, ou indireta, quando determinada expressão retoma outro referente já introduzido no texto e se associa indiretamente a ele.

A dêixis se define pela capacidade de criar vínculo entre o cotexto e a situação enunciativa em que estão os participantes do ato comunicativo (CAVALCANTE, 2014). Para melhor definição e estudo, a dêixis é classificada em seis tipos: pessoal, social, espacial, temporal, textual, memorial.

$\mathrm{Na}$ escola, quando os professores trabalham a referenciação em atividades de produção textual, muitas vezes, a atenção recai sobre as expressões referenciais de substituição, repetição e elipse, pela facilidade de ensinar esse conteúdo. Assim, os professores ficam sempre atentos para evitar a repetição insistente de determinada expressão referencial, não levando em conta que o referente é responsável pela coerência do texto. Ao avaliar a produção dos discentes, determinados professores apontam simplesmente para os "erros", sem trabalhar com precisão os sentidos que o aluno pode construir em seus textos ao fazer a opção por este ou por aquele referente. Entendemos que o papel do professor de Língua Portuguesa 
é fazer com que o aluno desenvolva a capacidade de observar os recursos expressivos que estão presentes em um texto e o quanto eles são responsáveis pelo dinamismo da construção de sentido no texto, de maneira a torná-lo capaz de construir textos melhores e se tornar mais competente do ponto vista comunicativo.

Em relação à construção dos referentes no texto, Cavalcante adverte que os

[...] referentes [...] estão sujeitos às 'artimanhas' das negociações intersubjetivas. O aprendiz, em sua prática de produção e leitura, deve ser estimulado a utilizar estratégias que explicitem a aplicação desse princípio. Ele deve entender que o uso da linguagem passa pela aceitação da audiência, o que demanda uma antecipação sobre como representar os referentes. Ao mesmo tempo, deve ser estimulado a 'negociar' com os textos que lê/escuta, dialogar para, a partir daí, participar, também ele, da construção dos conhecimentos oriundos dos textos. (Cavalcante, 2014, p. 39)

O objetivo do aluno é obter nota, assim busca cumprir o que o professor estabelece como critério de correção; ele não tem preocupação com a audiência, pois sabe que o professor é seu único interlocutor. Quanto ao professor, seu papel é mostrar ao aluno a importância da produção de textos e as artimanhas da linguagem, como é o caso da referenciação. É preciso estimular o estudante a refletir por meio da leitura de textos, de maneira a levá-lo a perceber a importância da referenciação. A nosso ver, só assim lerá com mais eficiência e, consequentemente, terá um olhar mais atento para suas produções, no sentido de recorrer a determinados recursos, como a referenciação, para que seus textos produzam o sentido esperado.

A produção textual é um processo árduo, tanto para o professor quanto para o aluno, mas, quando bem trabalhada, apresenta resultados satisfatórios. Isso envolve a sistematização, como destaca Passarelli (2012, p.147): "se o professor sistematizar a prática terá como ministrar instrução específica a respeito da produção textual, evidenciando ao aluno que, para melhorar sua redação, é necessário planejar, escrever um texto provisório, revisar e editar”. Desenvolver estratégias para sistematizar o processo de escrita é fundamental para os dois envolvidos: aluno e professor. A referenciação está no âmbito do que a autora denomina de guardião do texto, que é um componente que se mantém ativado durante todo o processo de produção "para zelar pela coerência do texto, valendo-se do bom senso do redator, de sua intuição e de seus sentimentos”. (PASSARELLI, 2012, p. 233)

A referenciação merece mais ênfase nas atividades de produção textual na escola, visto que é responsável pelo encadeamento das ideias, pela coerência, pela coesão, assim como pelo dinamismo de interpretação, pois o produtor do texto não faz a opção por este ou por 
aquele referente de maneira aleatória, ele precisa de conhecimento para fazer uma seleção adequada, o que reforça a importância de se trabalhar a referenciação.

Um breve exemplo para ilustrar nossa exposição: em 2017, o então prefeito de São Paulo, João Dória, e sua equipe estudaram oferecer como merenda aos alunos da Rede Municipal de Educação e à população carente um produto à base de alimentos vencidos que seriam processados. Nas notícias sobre esse alimento, alguns veículos de comunicação adotaram diferentes referentes para denominá-lo: O jornal Folha de São S.Paulo (18/10/2017) denominou-o de "farinata", o Estado de S.Paulo (26/10/2017), de "alimento granulado", e a revista Carta Capital (25/10/2017), de "ração humana". Por meio desse exemplo, podemos perceber a importância da escolha dos referentes na produção de sentidos, pois há uma diferença entre "alimento" e "ração", diferença não apenas semântica, mas também de posicionamento ideológico adotado pelo veículo de comunicação. Como salienta Santos (2015, p. 6), “não podemos nos esquecer das marcas ideológicas na linguagem. Não há signo neutro, não há linguagem totalmente objetiva, isenta de posicionamento; a imparcialidade na linguagem é um mito, uma ilusão".

Neste ensaio, buscamos refletir sobre a importância de considerarmos a referenciação, como processo de construção de sentido, no ensino de produção textual. A nosso ver, para ensinar e avaliar a produção de texto é necessário ter conhecimento especializado. Assim, é importante oferecer ao professor de Língua Portuguesa cursos de capacitação que lhe permitam conhecer e desenvolver as práticas de leitura e de escrita. Da mesma forma, no caso de estudantes de graduação em Letras, deve-se implantar disciplinas voltadas à metodologia de ensino de produção textual, para que eles entendam como a prática acontece e, ao mesmo tempo, desenvolvam seus papéis de leitor e produtor de textos. Depois que o professor desenvolver a sua leitura e sua escrita, estará apto a desenvolver metodologias de ensino de produção de texto, pois só é possível ensinar quando se faz parte do processo.

\section{REFERÊNCIAS}

APOTHÉLOZ, Denis; REICHLER-BÉGUELIN, Marie-José. Construction de la référence et stratégies de désignation. TRANEL. Travaux Neuchâtelois de Linguistique, Institut des sciences du langage et de la communication (Neuchâtel, Suisse), 1995. p.227-271.

CAVALCANTE, Mônica M. A construção do referente no discurso. Texto apresentado no módulo de formação continuada, publicado pela Fundação Demócrito Rocha. Fortaleza, 2003. 
CAVALCANTE, Mônica Magalhães; CUSTÓDIO FILHO, Valdinar; BRITO, Mariza Angélica Paiva. Coerência, referenciação e ensino. São Paulo: Cortez, 2014.

KOCH, Ingedore Grunfeld Villaça. Desvendando os segredos do texto. 7. ed. São Paulo: Cortez, 2014.

KOCH, Ingedore Grunfeld Villaça; MARCUSCHI, Luiz Antônio. Processos de referenciação na produção escrita. D.E.L.T.A, n. 14, p. 169-90, 1998.

PASSARELLI, Lílian Ghiuro. Ensino e correção na produção de textos escolares. São Paulo: Cortez, 2012.

SANTOS, Leonor Werneck. ReVel na Escola: Referenciação. ReVEL, v.13, n. 25, p. 1-8, 2015. Disponível em: <www.revel.inf.br>. Acesso em: 20 fev. 2019.

SILVA, Valney Veras da; CAVALCANTE, Mônica Magalhães; BRITO, Mariza Angélica Paiva. Referenciação nos estudos Críticos do Discurso. ReVEL, v. 13, n. 25, p. 278-294, 2015. Disponível em: 〈www.revel.inf.br〉. Acesso em: 2 mar. 2019. 